\title{
Hillslope hydrology under glass: confronting fundamental questions of soil-water-biota co-evolution at Biosphere 2
}

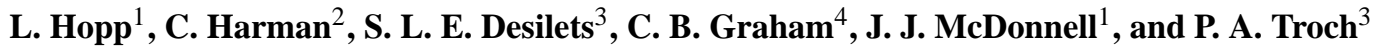 \\ ${ }^{1}$ Department of Forest Engineering, Resources and Management, Oregon State University, Corvallis, USA \\ ${ }^{2}$ Department of Geography, University of Illinois at Urbana-Champaign, USA \\ ${ }^{3}$ Department of Hydrology and Water Resources, The University of Arizona, Tucson, USA \\ ${ }^{4}$ Department of Crop and Soil Sciences, The Pennsylvania State University, University Park, USA
}

Received: 20 May 2009 - Published in Hydrol. Earth Syst. Sci. Discuss.: 18 June 2009

Revised: 29 September 2009 - Accepted: 16 October 2009 - Published: 6 November 2009

\begin{abstract}
Recent studies have called for a new unifying hydrological theory at the hillslope and watershed scale, emphasizing the importance of coupled process understanding of the interactions between hydrology, ecology, pedology, geochemistry and geomorphology. The Biosphere 2 Hillslope Experiment is aimed at tackling this challenge and exploring how climate, soil and vegetation interact and drive the evolution of the hydrologic hillslope behavior. A set of three large-scale hillslopes ( $18 \mathrm{~m}$ by $33 \mathrm{~m}$ each) will be built in the climate-controlled experimental biome of the Biosphere 2 facility near Tucson, Arizona, USA. By minimizing the initial physical complexity of these hillslopes, the spontaneous formation of flow pathways, soil spatial heterogeneity, surface morphology and vegetation patterns can be observed over time. This paper documents the hydrologic design process for the Biosphere 2 Hillslope Experiment, which was based on design principles agreed upon among the Biosphere 2 science community. Main design principles were that the hillslopes should promote spatiotemporal variability of hydrological states and fluxes, facilitate transient lateral subsurface flow without inducing overland flow and be capable of supporting vegetation. Hydrologic modeling was used to identify a hillslope configuration (geometry, soil texture, soil depth) that meets the design objectives. The recommended design for the hillslopes consists of a zero-order basin shape with a 10 degree overall slope, a uniform soil depth of $1 \mathrm{~m}$ and a loamy sand soil texture. The sensitivity of the hydrologic response of this design to different semiarid climate scenarios was subsequently tested. Our modeling showed that the timing of rainfall in relation to the tim-
\end{abstract}

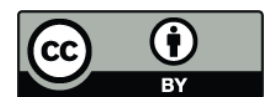

Correspondence to: L. Hopp

(luisa.hopp@oregonstate.edu) ing of radiation input controls the spatiotemporal variability of moisture within the hillslope and the generation of lateral subsurface flow. The Biosphere 2 Hillslope Experiment will provide an excellent opportunity to test hypotheses, observe emergent patterns and advance the understanding of interactions.

\section{Introduction}

In a number of recent papers addressing future directions in hydrology and related disciplines a common theme has emerged: that the spatial variability and temporal dynamics of the physical and biological processes controlling water movement in the landscape present a fundamental challenge to our ability to improve hydrologic prediction, particularly under changing climates and land uses (Sivapalan, 2005; McDonnell et al., 2007; Lin et al., 2006; Wagener et al., 2007; Tetzlaff et al., 2008; Soulsby et al., 2008; Dunn et al., 2008; Troch et al., 2009). There is recognition that observations of these processes represent only the current state of the continuing co-evolution of the hydrologic systems with the biota, soils, geomorphology and micro-climates that make up the critical zone (Brantley et al., 2007). This coevolution creates patterns of interdependency and connections between processes that may form the basis of new hydrologic theories that transcend the uniqueness of each catchment (Kumar, 2007). Therefore there is a direct tie between gaining a deeper understanding of the process interactions that occur in the landscape (and the patterns that emerge as a result of this interaction) and improving hydrologic prediction (Sivapalan, 2005). Field experiments to understand how and why hydrologic co-evolution occurs are fundamentally limited by unknown, and with today's instrumentation,

Published by Copernicus Publications on behalf of the European Geosciences Union. 
unknowable boundary conditions (McDonnell et al., 2007). In such open environmental systems, traditional field "experimentation" is limited largely to sampling for patterns of hydrological states and fluxes and sampling for model parameters (Eberhardt and Thomas, 1991). So how can we address our most fundamental research challenge of co-evolution in the short term, before the development of techniques that will allow us to illuminate our subsurface boundary conditions in the field? Controlled laboratory (indoor and outdoor) experiments may be an important way forward. There are a few examples of large-scale laboratories for environmental research, such as the Outdoor Streamlab of the St. Anthony Falls Laboratory (University of Minnesota), studying interactions between a channel, its floodplain and vegetation (http://www.safl.umn.edu/facilities/OSL.html, or the Artificial Catchment "Chicken Creek" in Germany (Gerwin et al., 2009). In hillslope hydrology, controlled experiments have in the past yielded extraordinary new insights into hydrological processes: Hewlett and Hibbert's (1963) concrete-lined hillslope experiment at the Coweeta Hydrologic Laboratory, North Carolina, USA, that exposed the role of soils for baseflow generation; the covered-roof experiments at Gårdsjön, Sweden, that illustrated chemical transformations in the subsurface with acid deposition (see Bishop and Hultberg, 1995 and many others); Kendall et al.'s (2001) Hydrohill, China, experiment that defined hillslope-scale flowpaths and mixing. While such experiments and many others have provided new insights into how and where processes operate with known boundary conditions, none have yet tackled why such processes occur from an evolutionary standpoint. Such experiments would require a degree of control of climate, soil and topography that has until now been unimaginable.

Here we report on plans for constructing and instrumenting three experimental hillslopes at Biosphere 2 near Tucson, Arizona, USA, in order to observe the coupling of geochemical, biological and physical processes, and the resulting co-evolution of the hillslope structure and properties through time. Biosphere 2 is a large-scale earth science facility under the management of The University of Arizona (www.b2science.org). The facility presents a unique opportunity to conduct large-scale physical experiments of landscape processes in a tightly controlled environment (Huxman et al., 2009). The hillslopes will be housed in three $33 \mathrm{~m} \times 18 \mathrm{~m}$ bays which will allow for controlling the atmospheric conditions and the monitoring of fluxes of water, solutes, sediment and gases with a precision that is not possible in the field, and at a scale that is infeasible in the typical lab setting. The hillslopes will be allowed to evolve over an anticipated lifespan of 10 years. The physical experiments will be complemented with efforts to develop a coupled process model that can be used to more deeply understand the interacting hydrological, biological and geochemical hillslope processes, and provide a basis for applying the lessons learned at Biosphere 2 to other systems. The facility will enable fundamental questions in hydrology to be ad- dressed, such as: How do simple assemblages of parent material, slope, climate and vegetation lead to complex hillslope system behavior? What controls subsurface flow network evolution? When does the heterogeneity introduced by the vegetation and weathering processes disable our ability to predict the water and energy balances? Tackling these questions amounts to a mechanistic assessment of the water balance unlike any work to date.

So how does one begin to design such a grand experiment? The spatial and temporal design of the Biosphere 2 Hillslope Experiment represents a novel challenge, as the initial structure of the hillslopes and the climatic forcing must be chosen such that the individual and collective objectives of the scientists involved are met. We are specifically pursuing an interdisciplinary approach to experimental design through cultivation of a collaborative group that brings together scientists from diverse disciplines such as hydrology, geomorphology, soil geochemistry, atmospheric science, ecology, and genomics. We follow the Platt (1964) approach to strong inference, where he and others since then, have noted that certain systematic methods of scientific thinking may produce much more rapid progress than others - most notably devising multiple working hypotheses, then devising one or more crucial experiments with alternative possible outcomes that can exclude one or more of the hypotheses (Platt, 1964, p. 347). In the case of Biosphere 2, the multiple working hypotheses revolve around two main research questions (Huxman et al., 2009): 1) How does water move through the landscape to streams? and 2) How does vegetation affect these flowpaths? The Biosphere 2 Hillslope Experiment will represent vast informational detail and complexity, where much time could be wasted on what Platt would call "low-information" observations or experiments if one does not think carefully in advance about what the most important and conclusive experiments would be for advancement of the field. Our philosophy has been to have a group of leading researchers in the different sub-fields debate every experiment ahead of time.

Here we present one small but important element of the overall Biosphere 2 Hillslope Experiment. We outline the hydrologic design of the Biosphere 2 Hillslope Experiment and report on some of the challenges and opportunities it creates for hydrologic research. These findings will form the basis for later development of multiple working hypotheses in this community experiment. The design reported here has been developed through discussions at a series of planning workshops at Biosphere 2, informed by hydrologic modeling efforts by the authors. It should be noted that the design presented here is only a preliminary recommendation from hydrologists in the Biosphere 2 scientific community, and does not necessarily represent the final design that will be used in construction. Companion papers to this paper explore potential interactions between hydrology and the geochemistry (Dontsova et al., 2009) and vegetation (Ivanov et al., 2009), respectively. Specifically, our paper focuses on the following questions: 
1. What are the key considerations and constraints that need to be incorporated into the hillslope design from a hydrologic perspective?

2. How can modeling methodologies and results be used to guide the design process and develop a base hillslope design?

3. What are the effects of different climate regimes (as possible treatments in the overall experiment) on the hydrologic behavior of the simulated base hillslope design?

The results of the design modeling will be used to further refine the design and generate hypotheses that can be tested against future observations. These design works provide a background to ultimately specifying the questions that the hillslopes might answer hydrologically - in particular, those that can be falsified within the spatial and temporal scales of the Biosphere 2 Hillslope Experiment framework. Ultimately, the usefulness of the Biosphere 2 experiments depends on the robustness of the hypotheses and questions that will be addressed using the hillslopes. This paper provides the structural underpinning for this next stage of research at the facility.

\section{Biosphere 2 hillslope design}

\subsection{Design criteria}

Our design of the Biosphere 2 hillslope incorporated nine principal criteria to ensure that the hillslopes would be capable of answering the key scientific questions posed by the community of scientists (Huxman et al., 2009). These criteria fall into three categories: (A) philosophical, (B) scientific and (C) practical and arose out of the discussions at the planning workshops.

A1. Minimize the imposed structure, and maximize the emergent structure. Observing the spontaneous emergence of structure within the hillslope is central to the scientific objectives of the Biosphere 2 project (Huxman et al., 2009). Therefore it is important to minimize the structure imposed on the hillslope by the initial conditions, for example through the spatial structure of the soils. This would not be possible if the hillslope was designed to mimic the structure of any particular hillslope observed in the field. However, this objective must be tempered by the fact that many common landscape properties, such as the surface and subsurface morphology of a hillslope, are the result of many thousands of years of development. It will be necessary to impose some structure on the system in order to create a hillslope that allows for some of the complex hydrological processes observed in the field.

A2. Simplicity and effectiveness. The Biosphere 2 experiments offer the chance to tackle questions related to process coupling in a way that has not been possible previously, but with this breadth of opportunity come the pitfalls of trying to do too much. There are cost and resource limitations on what can be achieved. It is not possible to simultaneously span multiple treatment dimensions (e.g. climate, soil type, vegetation type), and use the three bays for independent replicates. Nor is it possible to "reset" the hillslopes once the experiments have begun, except at significant cost. Therefore the hillslope experiment design must be simple (incorporating as few processes as is required to make the hillslope a useful model of natural complexity, and no fewer) and effective (be able to answer a large suite of questions and generate an interesting data set).

B1. Relevance of the results to the semi-arid setting of the Biosphere 2 facility. The facility is located in the Sonoran Desert, an area which has a mean annual rainfall of $330 \mathrm{~mm}$ and a mean annual potential evapotranspiration of $1600 \mathrm{~mm}$. The average minimum and maximum temperatures are $6^{\circ} \mathrm{C}$ and $18^{\circ} \mathrm{C}$ for January and $25^{\circ} \mathrm{C}$ and $38^{\circ} \mathrm{C}$ for July. While it is technically possible to simulate a wide variety of climates inside the Biosphere 2 dome, there are several reasons for choosing similar semi-arid climates. About $38 \%$ of the world's population live in semi-arid areas covering $41 \%$ of the earth's terrestrial surface (MEA, 2005). These areas are expected to be significantly affected by climate change, making research in these landscapes a priority (Reynolds et al., 2007). It is also more cost efficient to simulate a climate that is not too different from the outside.

B2. Spatially variable moisture regimes, including convergence. The convergence of lateral flows in channel heads and the differential soil moisture dynamics across hillslopes are an important driver of the evolving soil and vegetation spatial structure. These can drive the occurrence of "hot spots" where reactants and resources are brought together to produce disproportionately high rates of transformation of the hillslope. The chosen hillslope geometry should provide an opportunity to examine how lateral connectivity and convergence produce modes of spatial variability in soil moisture regimes, and the consequences of this variability on the hillslope evolution.

B3. Lateral connectivity of processes through transient subsurface flow. One of the unique opportunities of doing experimental hydrology at this scale is the ability to examine the role that lateral hydraulic connectivity across the hillslope plays in controlling the diversity and structure of physical, geochemical and biological processes. The saturated lateral flow that occurs in many hillslopes underlain by lowpermeability layers has been the subject of a number of theoretical, modeling and experimental studies in recent years (e.g. Woods and Rowe, 1996; Tani, 1997; Buttle and McDonald, 2002; Troch et al., 2003; Tromp-van Meerveld and McDonnell, 2006a, b; Kampf and Burges, 2007; Fiori and Russo, 2007) because of its importance in runoff generation and controlling the export of leached mineral and nutrient species (e.g. van Verseveld et al., 2008; McHale et al., 2002). The hillslope was designed to facilitate the occurrence of this 
process. Although lateral subsurface flow as a runoff process is considered to be more important in humid areas, it does occur in semi-arid areas (Lyon et al., 2008; Newman et al., 1998; McNamara et al., 2005).

B4. Ensuring sufficient water availability in the root zone. A key component of the scientific research planned for the hillslopes is concerned with the dynamics of grasses and shrubs that will be planted, most likely in several stages over the course of the experiment. Highly conductive soils like sands and gravels tend to have low water retention capacities, which could lead to desiccation of the vegetation during the dry season. Thus, in designing the hillslope there is a need to find a balance between avoiding overland flow (see C1) and maintaining sufficient water retention capacity.

B5. Temporal dynamics and response to climatic variation. Similar to spatial variability, the temporal variability of the soil moisture regime can drive processes that would not occur under an (unrealistic) constant soil moisture condition. "Hot moments" can occur (typically in conjunction with "hot spots") that contribute disproportionately to the system dynamics and evolution (McClain et al., 2003). To examine this important class of phenomena, it is crucial that the temporal variability of a realistic semi-arid precipitation and radiative forcing regime is preserved in the Biosphere 2. The experiment is also an opportunity to more deeply understand how the temporal variability of the climate and its control on water availability and atmospheric water demand influences vegetation dynamics in semiarid areas.

C1. Avoiding significant erosional overland flow. Surface erosion is an example of a hot spot/hot moment that could have a potentially catastrophic effect on the experiment. While the evolution of the microtopography of the hillslopes will be one focus of research, the hillslopes must be designed to avoid large-scale gullying or mass wasting. In the experiment mass wasting could occur if slopes are too steep. Overland flow could initiate gullying if soils become saturated to the surface, or if precipitation rates exceed infiltration rates. Both of these can be avoided for a given set of infiltration inputs to the soil by the selection of a soil with sufficiently high saturated hydraulic conductivity. Once a soil texture is chosen rainfall rates will be adjusted such that the generation of overland flow is minimized. Even so, it is expected that rain-splash and localized overland flow will cause some movement of surface sediments, generating surface microtopography.

C2. Technical feasibility. In addition to the considerations discussed above, there are constraints on the hillslope configurations imposed by the technical feasibility of constructing hillslope structures at this scale within the Biosphere 2. In many cases these constraints were identified during the design process through consultation with engineers and contractors.

Designing a hillslope that satisfies all of these considerations is complicated by the very knowledge-gaps that the hillslope experiment is aimed at addressing. Once the hillslopes are constructed, it is difficult to predict how they will evolve due to the network of process connections. Because of these uncertainties, in this paper we will restrict our discussion to the modeling that was done to design the initial configuration of the hillslope, which will consist of a uniform soil material and no vegetation. For a more detailed analysis of the interplay between hydrology and geochemistry and vegetation, respectively, readers are referred to the companion papers by Dontsova et al. (2009) and Ivanov et al. (2009).

\subsection{A priori design decisions}

It was suggested in an early stage in the workshops that the basic design should consist of three hillslopes with identical geometry and soils. They could be subjected to various climates, and be seeded with various vegetation types, with subsequent vegetation evolution through time (Huxman et al., 2009). Assuming these parameters were fixed, the key decisions to be made from a hydrologic perspective concerned the following parameters: 1) hillslope surface topography, 2) subsurface topography, 3) permeability of the base, 4) overall slope, 5) soil depth and 6) soil texture (i.e. hydraulic properties of the soil)

These parameters must be chosen before construction of the hillslopes can begin. Values of these parameters for a proposed design were based on the design considerations listed above and informed by hydrologic modeling. However, a number of basic decisions were made prior to the bulk of the modeling efforts. A zero-order basin geometry was identified as providing a realistic landscape form that would promote transient saturated lateral subsurface flow (B3) and spatial and temporal variability of soil moisture and water table development (B2, B5), as compared to a simpler planar hillslope with uniform slope. This represents a degree of structure imposed on the system, rather than arising spontaneously (A1), but was regarded as essential to meeting the objectives. While soil depths are often highly variable at the hillslope scale (Freer et al., 2002), it was decided - in the interests of imposing as little initial structure as possible (A1) and for the sake of simplicity (A2) - that the soil depths should be uniform throughout the domain, meaning that the base and surface topographies be identical. The basic geometry used for going forward with the modeling work is shown in Fig. 1. Since bedrock permeability has been shown to be a first-order control on hillslope hydrological processes (Tromp-van Meerveld and McDonnell, 2006b), introducing a permeable base was considered, and efforts were made to model the effects of bedrock permeability on the hillslope flows. However, this component was abandoned for reasons of simplicity (A2) and technical feasibility (C2).

Thus, the design modeling described in the following sections focused on the remaining three parameters overall slope angle, soil depth and soil texture. 


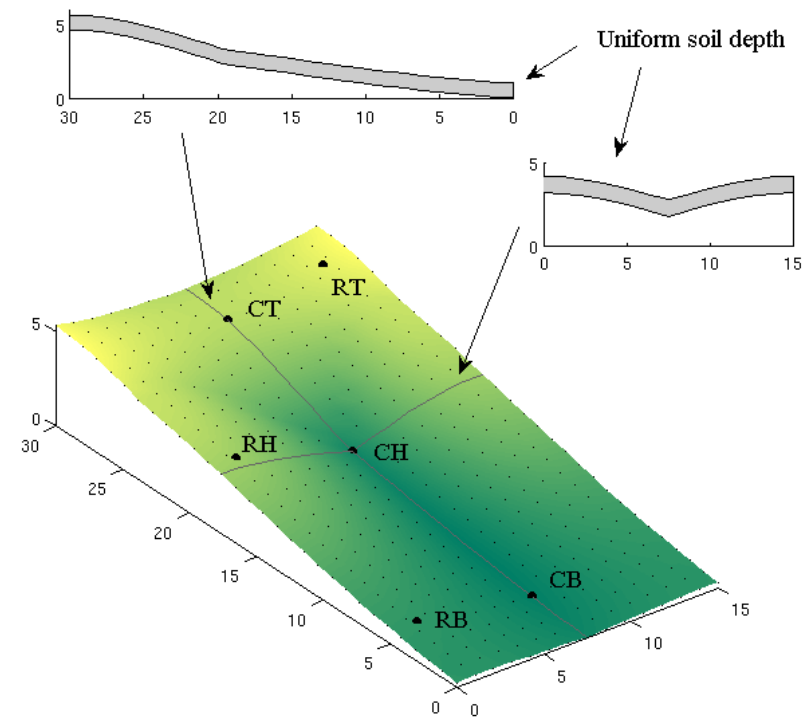

Fig. 1. Basic geometry of the proposed hillslope surface and base is a zero-order (unchannelized) basin with overall dimensions $30 \mathrm{~m}$ by $15 \mathrm{~m}$.

\subsection{Modeling approach}

Hydrologic modeling was used in a two-stage approach to investigate the parameter space for the remaining parameters to be determined and to analyze the hydrologic behavior of different hillslope designs. Major hillslope hydrological processes that we expect include infiltration of rainfall, unsaturated flow and saturated lateral subsurface flow, and models used for the design modeling were selected accordingly. First, a parsimonious modeling scheme was used that could be run rapidly and sample a large region of the parameter space. Metrics were identified to determine regions of the parameter space that conformed to the design considerations. This constrained the parameter space that was subsequently explored in detail by a more complex model.

Selection of the precise climate properties (precipitation, temperature, wind-speed, humidity, radiation etc) is not immediately necessary and can be deferred. However, since the performance of the hillslopes depends on the climate that is applied to it, representative climates were used in the design process. The sensitivity of the recommended design to climate was assessed in this study (see Sect. 3), and explored in more detail in Ivanov et al. (2009). For this design modeling a rainfall scenario representative of a semiarid Sky Island forest (Brown-Mitic et al., 2007), a subset of the US western sub-alpine forest, was generated as a marked Poisson point process with a semi-annual total rainfall of $367 \mathrm{~mm}$ distributed over 90 days (34 storms, maximum intensity $7.9 \mathrm{~mm} \mathrm{~h}^{-1}$, storm duration $4 \mathrm{~h}$ or $8 \mathrm{~h}$, maximum storm size $31 \mathrm{~mm}$, interstorm period ranging from $8 \mathrm{~h}$ to $212 \mathrm{~h}$ ), followed by a dry period of 90 days (see Fig. 3 for the rainfall scenario used in the design modeling). Multiple climates were not considered in detail in the design modeling process, which focused on the physical properties of the hillslopes that were needed to begin the engineering design and construction.

\subsubsection{Initial modeling: constraining the parameter space}

The initial modeling was carried out using tools that could provide answers to pressing design questions quickly, allowing the more detailed modeling to go forward. For this reason, models were used that were familiar to the design team, and ran quickly. The initial modeling focused on identifying an overall slope angle and a soil texture and soil depth that would allow for lateral flow (B3), avoid overland flow (C1), and have sufficient water holding capacity to sustain vegetation (B4). The mean slope was varied by linearly scaling the elevations of a base digital elevation model (DEM).

The initial modeling consisted of a 1-D model of infiltration through the unsaturated zone using an approximation of the Richards' equation known as a Multiple Wetting Front model (Struthers et al., 2006). This model predicts fluxes through a free-draining unsaturated zone of fixed depth. Evapotranspiration processes are modeled as a fraction of the (seasonally varying) potential rate, where the fraction depends on the relative saturation of the entire unsaturated zone. Overland flow occurs if the precipitation rate exceeds the saturated hydraulic conductivity. The lower boundary output (recharge or leakage) of this unsaturated zone model was used as input to a simple 2-D model of saturated flow through a hillslope domain based on the Boussinesq equation (Harman and Sivapalan, 2009). This model predicts the build-up of the saturated zone, and the lateral flow over the bed and downslope towards the hillslope lower boundary. The lower boundary condition is kinematic (i.e. the water table gradient is parallel to the local bed slope), so the subsurface flow drains freely. In this modeling approach the water table dynamics are decoupled from the unsaturated zone depth, so that the depth of the unsaturated zone is fixed, even when the water table has saturated a depth equivalent to the assumed unsaturated soil depth. For this reason the results should be interpreted with particular caution. The model does not simulate saturation excess overland flow and return flow (exfiltration).

The model was run using the generated semi-arid Sky Island forest rainfall scenario and with other parameters varied as follows:

- Two scenarios of potential evapotranspiration: one at $500 \mathrm{~mm} \mathrm{a}^{-1}$ and one at $1000 \mathrm{~mm} \mathrm{a}^{-1}$, both varying seasonally according to a sinusoidal curve out of phase with the precipitation, with an amplitude of $250 \mathrm{~mm} \mathrm{a}^{-1}$ and $500 \mathrm{~mm} \mathrm{a}^{-1}$, respectively. Diurnal variations were not considered. 
- Four unsaturated zone depths: $0.5 \mathrm{~m}, 1 \mathrm{~m}, 1.5 \mathrm{~m}$ and $2 \mathrm{~m}$.

- Twelve soil texture classes: van Genuchten (1980) soil hydraulic parameters were used for each of the standard USDA soil texture classes, obtained from class averages in the Rosetta database (Schaap et al., 2001).

Simulations were run initially with an overall slope of 6 degrees. In addition, the sensitivity to slope was examined for a subset of the parameter sets for overall slopes ranging from 2 degrees to 16 degrees. Two metrics were used to interpret the results of the initial modeling. First, the ratio $R_{w}$ of total lateral subsurface flow to the total precipitation over the 180 day simulated period gives an indication of the water balance (though it does not account for the partition between overland flow, evapotranspiration and storage remaining in the hillslope at the end of the modeled period). A very high value of this metric $\left(R_{w}>0.8\right)$ would suggest that the hillslope drains too quickly, and does not store sufficient water for transpiration (B4). Low values $\left(R_{w}<0.2\right)$ suggest that either there is minimal subsurface flow (B3), or overland flow dominates (C1).

Second, the ratio $R_{S}$ of the peak saturated thickness and the assumed depth of the unsaturated zone was calculated to examine the likelihood of overland flow. Because the watertable feedback between saturated and unsaturated models is not accounted for in this parsimonious model approach, we cannot predict saturation to the surface directly. However, if we take the assumed depth of the unsaturated zone as representing the whole soil depth, the region of the parameter space that produces a saturated thickness of similar or larger depth is likely to produce saturation excess overland flow in a coupled model. Thus parameter sets that produce small values of this ratio $\left(R_{S}<0.8\right)$ will be less likely to produce overland flow $(\mathrm{C} 1)$.

The values of the two metrics, $R_{w}$ (y-axis) and $R_{S}$ (x-axis), for each of the parsimonious modeling simulations are plotted against each other in Fig. 2. This figure also shows the region that meets the design criteria set out in the above discussion. Only the two simulations with a $2 \mathrm{~m}$ thick loamy sand produced results that fell within the design region. The very high permeability of sandy soils allowed all incoming precipitation to be translated quickly into subsurface runoff. Consequently, only a very small fraction was available to sustain vegetation. For all other soils except loamy sand, the permeability was too low, and the majority of precipitation either evaporated before it reached the base of the unsaturated zone, or lateral flow rates were too low, producing a build up of the water table within the hillslope.

Varying the slope was found to have a second-order effect on the dynamics of the water balance (results not shown). A higher slope produced a higher peak discharge, but its effect on the likelihood of saturation was minor. At low slopes more water remained in the hillslope, but it was distributed

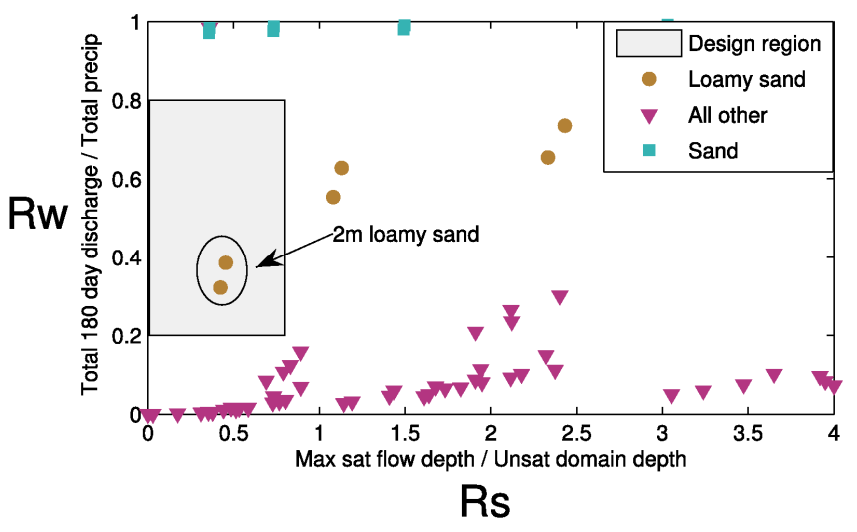

Fig. 2. Performance of various combinations of design parameters evaluated against the design metrics $R_{S}$ and $R_{w}$. Results are shown for the 6 degree mean slope angle. The grey box indicates the combinations of the design metrics that meet the design specifications.

between the swale and the side slopes. At high mean slope, the water table drained more quickly, but there was a higher degree of convergence in the swale, increasing the water table depth slightly compared to the lower slopes.

These results suggested that a texture of loamy sand with relatively high hydraulic conductivity, of the order of $1 \mathrm{~m} \mathrm{~d}^{-1}$ (Table 1), would be required to meet the design considerations. They also suggested that the soil depth is a critical control on whether lateral flows, but not surface saturation, occurred in the hillslope. These considerations informed the more detailed modeling using HYDRUS-3D.

\subsubsection{HYDRUS-3D modeling: exploring lateral subsur- face flow and spatiotemporal patterns of moisture}

HYDRUS-3D, a three-dimensional finite element model that solves the Richards' equation for variably saturated flow (Simunek et al., 2006; Simunek et al., 2008), was subsequently used to explore the effects of slope angle and soil depth on lateral subsurface flow and internal moisture distribution. As an initial base case, the zero-order basin geometry with a 20 degree overall slope and $1.5 \mathrm{~m}$ soil depth was chosen. Using this base case, the slope angle was changed to 10 degrees and 30 degrees, respectively, and the soil depth was changed to $1 \mathrm{~m}$ and $2 \mathrm{~m}$, respectively, resulting in five different scenarios. Based on results of the initial modeling, a loamy sand soil texture was chosen. Soil hydraulic parameters for the van Genuchten-Mualem soil hydraulic model (van Genuchten, 1980) were obtained from the Carsel and Parrish soil catalog (Carsel and Parrish, 1988) (Table 1). The flow domain was discretized based on a $1 \mathrm{~m}$ by $1 \mathrm{~m}$ DEM with a vertical spacing between mesh layers of $0.1 \mathrm{~m}$. The initial conditions were defined in the pressure head, starting with a uniform pressure head of $-0.5 \mathrm{~m}$ throughout the model domain, followed by a 10 day drainage period. An atmospheric boundary condition including hourly records of 
Table 1. Soil hydraulic parameters used in the design modeling (initial modeling and detailed modeling) and the climate testing modeling. In the initial modeling, the twelve soil textural classes of the USDA soil classification were tested (using the ROSETTA database) but only the parameters of loamy sand that was the selected texture for subsequent modeling are listed.

\begin{tabular}{lccccc}
\hline Model step & $\theta_{r}\left[\mathrm{~m}^{3} \mathrm{~m}^{-3}\right]$ & $\theta_{s}\left[\mathrm{~m}^{3} \mathrm{~m}^{-3}\right]$ & $\alpha\left[\mathrm{m}^{-1}\right]$ & $n[-]$ & $K_{s}\left[\mathrm{~m} \mathrm{~h}^{-1}\right]$ \\
\hline design: initial & 0.049 & 0.39 & 3.47 & 1.747 & 0.044 \\
design: detailed & 0.057 & 0.41 & 12.4 & 2.28 & 0.146 \\
climate testing & 0.062 & 0.41 & 9.13 & 2.02 & 0.078 \\
\hline
\end{tabular}

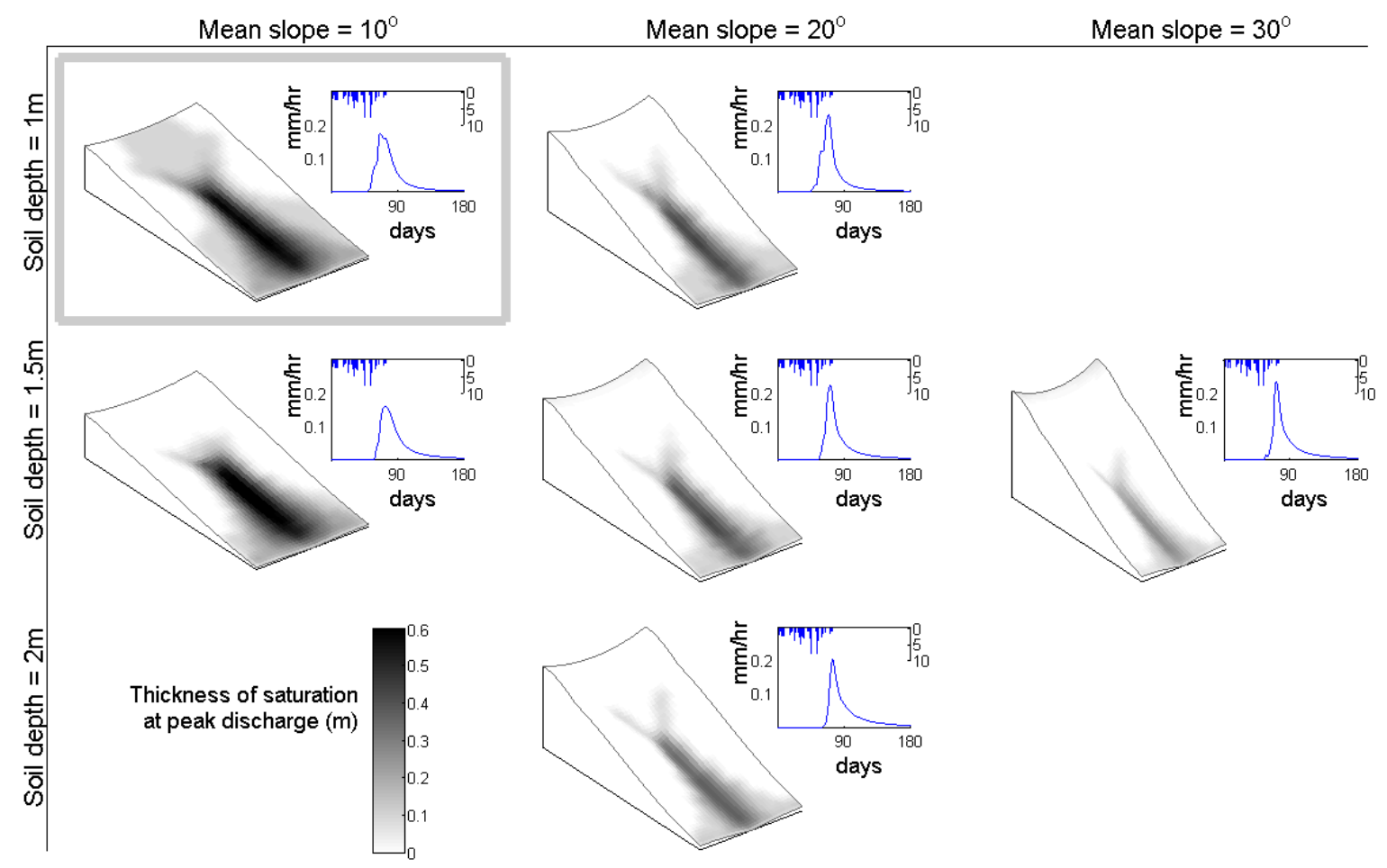

Fig. 3. Subsurface flow hydrographs and spatially distributed thickness of saturation for the slope angle and soil depth variations of the initial base case, simulated with HYDRUS-3D. Thickness of saturation is shown for the time step at which peak discharge occurred. Also shown are the results for the final design (10 degree overall slope and $1 \mathrm{~m}$ soil depth).

precipitation (the same generated semi-arid Sky Island forest rainfall scenario that was used in the initial modeling) and of potential evaporation rates was specified at the surface of the domain. Potential evaporation was modeled as a sinusoidal curve, with the maximum potential evaporation $\left(4.5 \mathrm{~mm} \mathrm{~d}^{-1}\right)$ at the start of the rainy season (start of simulation), dropping to $1 \mathrm{~mm} \mathrm{~d}^{-1}$ at 180 days. This seasonal evaporation trend was overlain with a truncated sinusoidal diurnal variation, assuming $12 \mathrm{~h}$ of evaporation during the day and $12 \mathrm{~h}$ of no evaporation during the night. Total modeled potential evaporation was $1000 \mathrm{~mm} \mathrm{a}^{-1}$. The downslope boundary of the hillslope consisted of a seepage face where water can leave the domain laterally through the saturated part of the boundary.
For all five scenarios simulated with HYDRUS-3D, subsurface flow accounted for approximately $33 \%$ of the rainfall, with actual evaporation accounting for the remaining $67 \%$. The hydrographs of the lateral subsurface flow consisted of one seasonal peak, with little response to individual storm events (Fig. 3). With decreasing soil depth, subsurface flow started earlier and also peak discharge was slightly higher and occurred earlier. Increasing the slope angle had a slight intensifying effect on the hydrologic response as well.

Contrary to the parsimonious modeling results, saturation of the entire profile did not occur in any of the scenarios (Fig. 3), meaning that saturation excess overland flow was successfully avoided with the chosen soil texture and the tested slope angle and soil depths (C1). In each simulation, a transient water table developed at the base of the flow 
domain as a response to the rainfall, rising up to $0.6 \mathrm{~m}$ in the profile. Figure 3 also shows the general pattern of moisture distribution with high relative saturation in the soil profile in the swale and towards the downslope boundary and drier zones upslope and on the side ridges (B2). The percentage of area that experienced saturation in the soil profile increased markedly at lower slope angles and also with shallower soils. The main flow path in downslope direction was in the swale, and the bulk of the subsurface flow left the domain around the center of the downslope boundary.

Discrepancies in the occurrence of saturation between the parsimonious and more complex modeling can be ascribed to three sources: 1) difference in model structure, 2) differences in soil parameters and 3) differences in climatic forcing. The simple model did not account for a range of processes, including capillary rise and the variable moisture of the unsaturated zone that can significantly affect the position of the water table. The detailed modeling used soil parameters from the Carsel and Parrish (1988) soil catalogue, which predicts a higher hydraulic conductivity for loamy sand than the Rosetta class averages. While this appears inconsistent it is not unreasonable to adopt a higher design conductivity given the high variability in conductivity values within a class, and the fact that these are design suggestions for a soil that will be manufactured, rather than estimates of a real soil. Thirdly, the climate scenarios used in the parsimonious modeling were refined for the HYDRUS-3D modeling to include a more accurate representation of the timing of the seasonality of evapotranspiration relative to precipitation, and to include diurnal variations. The improved representation of seasonality led to higher potential ET rates coinciding with water availability to increase the proportion of water lost as ET in the shallower soils. Together these three aspects led to a much reduced water table in HYDRUS-3D results.

\subsection{Recommended design}

The results of the design modeling were presented to and discussed with the Biosphere 2 scientific community. Balancing the principal design criteria and technical constraints (e.g. construction stability) led to a refined final design of the hillslopes that was used for further modeling work (e.g. Ivanov et al., 2009). This refined design consisted of the zero-order basin geometry with a 10 degree overall slope and a $1 \mathrm{~m}$ soil mantle with a loamy sand soil texture (see Fig. 3 for hydrograph and spatial pattern of thickness of saturation). As with all the HYDRUS-3D design simulations, the rainfall was partitioned in approximately $33 \%$ lateral subsurface flow and $67 \%$ evaporation.

Pressure heads near the surface were strongly influenced by atmospheric fluxes, i.e. infiltration and evaporation, whereas pressure heads in deeper zones did not show distinct responses to the dynamics of atmospheric fluxes (Fig. 4). Transient water tables, i.e. positive pressure heads, developed in the swale (locations $\mathrm{CH}$ and $\mathrm{CT}$ ) over the course of the

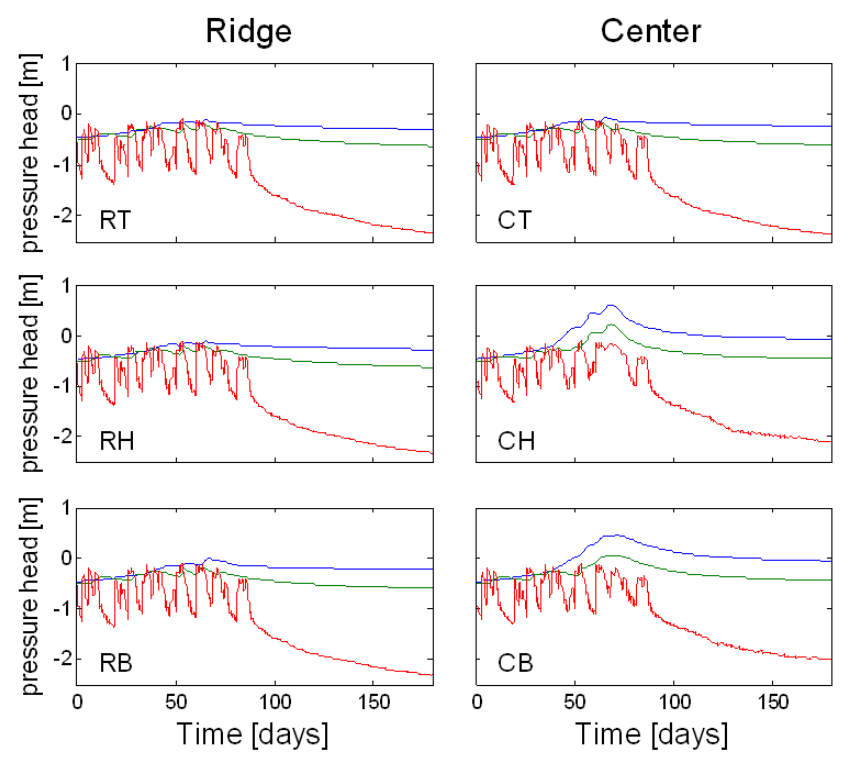

Fig. 4. Pressure head time series at six different locations in the hillslope (see Fig. 2 for locations) and in three depths per location (red: $0.1 \mathrm{~m}$ below surface, green: $0.5 \mathrm{~m}$ below surface, blue: $0.9 \mathrm{~m}$ below surface) for the recommended final design.

rainy season. The comparison with the hydrographs in Fig. 3 showed that subsurface flow did not start until transient water tables developed. This behavior is consistent with observations from experimental hillslope sites (Tromp-van Meerveld and McDonnell, 2006b). The simulation demonstrated that the chosen zero-order basin shape with a 10 degree overall slope and $1 \mathrm{~m}$ soil depth promotes spatially as well as temporally variable moisture regimes (design considerations B2 and B5), ranging from zones that experienced saturated conditions for extended periods of time (predominantly in the swale) to zones that remained unsaturated.

The actual design of the toe of the hillslope has not been decided yet. One option could be to construct a transition into a gravel or sand buffer and a permeable screen, with additional options to measure both surface and subsurface water flow. Once the toe design has been finalized additional simulations may become necessary as the toe design will influence the buildup of saturation along the seepage face and hillslope discharge.

\section{Testing three different semi-arid climate scenarios}

\subsection{Modeling approach}

One suggestion for the temporal design of the experiment has been to apply three different climates to the hillslopes (Huxman et al., 2009). This was the motivation to test three different climate scenarios that represent common rainfall distribution in semi-arid regions, using the proposed final hillslope design and the model HYDRUS-3D. The objective was 
to evaluate the importance of the relationship between timing of rainfall and radiation input for the hillslope hydrologic response. These climate scenarios were different to the one used in the design modeling. The first scenario consisted of a climate with $60 \%$ of the rainfall falling during three months of summer and another third during the six winter months. This means that the majority of rainfall is falling during the months with high radiative input, a climate typical, for example, of the southwest of the United States. For this scenario, meteorological data from 2001 from the Lucky Hills site within the USDA-ARS Walnut Gulch Experimental Watershed, Arizona, USA, were used as atmospheric boundary conditions (for site description see e.g. Scott et al., 2000). A second scenario adopted the same radiation input but with the rainfall from the original scenario shifted by six months, so that the majority of rain fell in winter. This created a climate with the maximum of rainfall and maximum of radiation input being out of phase, as is typically the case in Mediterranean climates (such as southern Europe, southern California and southwestern Australia). In a third scenario, the same radiation input was again used but the rainfall was distributed statistically uniformly throughout the year.

Total annual rainfall was $371 \mathrm{~mm}$ for all three scenarios. The uniform distribution of rainfall was generated stochastically as a Poisson process with approximately the same distribution of storm durations, interstorm periods, and mean intensities as the original data. The generated interstorm duration and storm duration were exponentially distributed whereas the storm depth was gamma-distributed (Ivanov et al., 2009). Maximum rainfall intensities in the summer and winter rain climate were $20 \mathrm{~mm} \mathrm{~h}^{-1}$ whereas intensities in the uniform rainfall distribution did not exceed $5.5 \mathrm{~mm} \mathrm{~h}^{-1}$. The hillslope was assumed to be free of vegetation. Potential evaporation fluxes were calculated with the Penman-Monteith combination equation that combines radiation and aerodynamic terms (Monteith, 1981; Monteith and Unsworth, 1990) using hourly records of air temperature, relative humidity, wind speed and net radiation from the Lucky Hills site. Calculated annual potential evaporation was $1545 \mathrm{~mm}$.

In order to avoid numerical instabilities due to the high evaporative fluxes at the soil surface, soil hydraulic parameters were changed to values between those of loamy sand and sandy loam (Table 1). This modification also reflected the preliminary results of particle size analyses performed in the meantime with various potential soil materials for the Biosphere 2 hillslope construction (Jon Chorover, personal communications). A one year simulation of the same respective climate was used as initial condition. Apart from these changes, the model setup was identical to the simulation of the final design. Total simulation time was 365 days for each climate scenario.
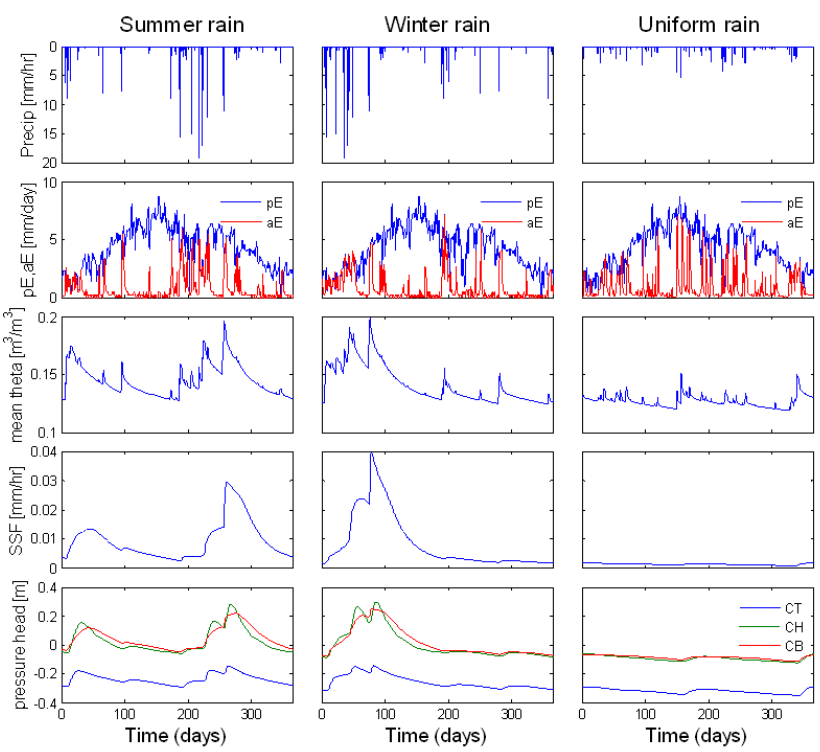

Fig. 5. Hydrologic hillslope response to three different semi-arid climates, simulated with HYDRUS-3D. SSF is the lateral subsurface flow, mean theta is the mean volumetric water content, averaged over the entire flow domain, $\mathrm{pE}$ and $\mathrm{aE}$ are potential and actual evaporation, respectively. Pressure head time series from $0.9 \mathrm{~m}$ below the surface for the three locations in the center of the domain (see Fig. 2).

\subsection{Results}

Although the total annual rainfall was the same for all three scenarios, the differences in rainfall timing resulted in marked differences in boundary fluxes (actual evaporation, lateral subsurface flow) and internal moisture dynamics (Fig. 5). The summer rain scenario produced two peaks in lateral subsurface flow. A smaller peak occurred during the winter months because, although storm sizes were smaller compared to the summer events, the atmospheric demand was low during those months leading to higher lateral subsurface flow generation. In summer, storm sizes were large enough to produce subsurface runoff despite the high potential evaporation. The winter rain scenario produced only one major peak in lateral subsurface flow in the winter months. The storms in summer, when the radiation input was at its maximum, were too small and infrequent to result in significant subsurface runoff. The uniform rainfall climate, despite having the same total rainfall amount, did not produce a major peak in subsurface flow, and flow rates remained at a low and relatively constant level. Surface runoff did not occur in any of the simulations. The pressure head time series demonstrated again that the presence of a transient water table was required to trigger a significant subsurface flow response. No transient water tables developed in the case of the uniform rainfall climate, whereas the occurrence of transient saturation in the summer and winter rain scenarios preceded the 
rise of the lateral subsurface flow hydrograph. Subsurface runoff accounted for approximately $20 \%$ of the total rainfall in both the summer rain and winter rain scenarios and less than $5 \%$ in the case of the uniform rainfall distribution. The mean water content (mean theta in Fig. 5), averaged over the entire hillslope, represents a measure for storage. The summer rain and winter rain climates both led to a higher temporal variability of hillslope soil moisture storage, ranging between 0.12 and $0.2 \mathrm{~m}^{3} \mathrm{~m}^{-3}$ (Fig. 5, mean theta). The uniform rainfall scenario showed considerably less variations over time. Comparing the mean theta, subsurface flow and pressure head curves suggests that a mean water content of $0.16 \mathrm{~m}^{3} \mathrm{~m}^{-3}$, corresponding to $38 \%$ relative saturation of the hillslope, is required to lead to the development of a transient water table and, thus, to significant lateral subsurface flow. The uniform rainfall distribution with frequent, low intensity storms did not produce sufficient filling of storage and the development of transient water tables, a prerequisite for the generation of significant lateral subsurface flow.

Because only bare soil evaporation was considered, the actual evaporation is primarily controlled by the near-surface soil moisture conditions. Because of the relatively coarse texture of the soil material used in the simulations, the water content of the soil near the surface quickly dropped to residual water contents during dry periods, and the upward transport of water from deeper regions became negligible. Therefore, the ratio between actual and potential evaporation was significantly less than unity $(19 \%$ for the summer rain climate, $18 \%$ for the winter rain climate and $22 \%$ for the uniform rainfall scenario). Actual evaporation was high only during and shortly after storms and decreased strongly during interstorm periods. While pressure heads at the soil surface reached very low values due to evaporation, pressure heads in the rest of the domain remained greater than $-4 \mathrm{~m}$, indicating that sufficient water would be available to support vegetation in these climate scenarios.

The simulation of the three semi-arid climates showed the importance of the relative timing between rainfall and potential evaporation (i.e. surface energy input) for the movement of water in the hillslope. The interplay between evaporation and infiltration determines the amount of water that is available for percolation into deeper zones, filling of storage and the generation of lateral subsurface flow. Under the assumed high radiation input typical for the region surrounding the Biosphere 2, either a number of large more intense storms during the summer months and/or sufficiently large storms during the winter months are required to ensure temporal variability of the hillslope moisture regime (B5) and to initiate lateral hillslope-scale hydraulic connectivity (B3).

\section{Discussion}

\subsection{Difficult tradeoffs in the Biosphere 2 hydrologic design}

The process of designing an experiment like the Biosphere 2 hillslopes is clearly different from traditional benchtop-scale and hillslope-scale efforts of the last few decades. Laboratory experiments are generally designed around a focused question or set of questions, and the experimental systems are greatly simplified with respect to scale and boundary conditions compared to the real world. Classic works that have isolated hillslope segments at the benchtop-scale (Anderson and Burt, 1977) or hillslope scale (Hewlett and Hibbert, 1963) are examples of where a clear experimental design mapped to a singular research question led to new breakthroughs on discovery of particular flow processes (e.g. the role of soil drainage on maintenance of stream baseflow as shown by Hewlett and Hibbert (1963)). More recent examples at the benchtop-scale (i.e. Kosugi et al., 2004) and hillslope-scale (i.e. Kendall et al., 2001) have continued in this tradition of isolating single features of a system and elucidating particular flow processes (e.g. macropore flow contributions to pore pressures or stream chemistry dynamics).

The Biosphere 2 design is different to these previous focused efforts. It is perhaps more akin to what was attempted with the roof-covered catchment experiment at Gårdsjön, Sweden (see Bishop and Hultberg, 1995 and many others) where compromises where made to accommodate interdisciplinary research and multi-faceted research objectives. Identifying the fundamental considerations that transcended the individual scientific objectives of each scientist involved in the experimental design of the Biosphere 2 hillslopes provided the conceptual scaffolding on which the details of the design could be built. These considerations emerged from a long period of interactions, in a way analogous to the emergence of complexity expected in the hillslope experiment itself. Inevitably, the design criteria and considerations themselves limit the type of questions that can be answered with this hillslope design, e.g. by minimizing the occurrence of certain processes such as overland flow. Nevertheless, the focus of the overall Biosphere 2 experiment is to advance the understanding of critical zone processes (Huxman et al., 2009). We argue that the presented hillslope design will allow us to better understand how hydrological, biological and geochemical processes interact, creating subsurface structure and temporal patterns.

The overall Biosphere 2 hydrological design was constrained by philosophical, scientific and technical considerations. However, decisions made even before these tradeoffs were discussed philosophically, scientifically and practically as a group also shaped the final design - quite profoundly - in three ways: (1) we chose not to replicate a previously well-studied hillslope, (2) we chose an impermeable lower 
boundary and (3) we chose a convergent hollow as our topographic blueprint.

So why did we choose to not replicate a previously wellstudied hillslope? Previous trenched hillslope experiments at a scale very similar to the Biosphere 2 hillslope bays have been completed in the past decade at Georgia, USA (Freer et al., 2002), New Zealand (Woods and Rowe, 1996), Oregon, USA (McGuire et al., 2007), Japan (Uchida et al., 2005) and Canada (Buttle and Turcotte, 1999). Intense discussion revolved around possibly replicating one of these systems within the Biosphere 2 bays. The main rationale for not choosing to replicate an existing site was the awkward juxtaposition of site specificity with local climate constraints. While the Biosphere 2 climate can be controlled, it seemed that imposing the boundary conditions from a very different geographic setting might condition the results too greatly for the Biosphere 2 experiments. The more generic hillslope form - as described in this paper - was agreed upon as a better option for initial conditions that would best serve the overall goals of the project.

We chose an impermeable lower boundary for our Biosphere 2 slopes largely out of practicality. Bedrock permeability has been shown in several recent hillslope studies to influence the development of transient saturation (Ebel et al., 2008) and connectivity of saturated patches at the soilbedrock interface (Hopp and McDonnell, 2009). Several recent field studies have quantified bedrock permeability at the hillslope scale through sprinkling experiments (e.g. Trompvan Meerveld et al., 2007) so that some bedrock permeability values are already known. In the end, the issue of bedrock permeability was "decided" based on technical feasibility. It was not possible, within the constraints of the budget, to consider how a permeable bedrock might be incorporated into the design and how that water would be sampled, recycled and linked to the soil mantle above. This was a difficult constraint to accept as we know that fully impermeable bedrock is not found in nature and will condition lateral flow processes and experimental results. Artificial hillslopes constructed in the past have also used impermeable bedrock (usually poured concrete) as the layer below the soil (e.g. Hewlett and Hibbert (1963) at Coweeta Hydrologic Laboratory; Kendall et al. (2001) at Hydrohill, China). Based on these findings and other work from natural experimental hillslopes, we know a priori that the impermeable bedrock at Biosphere 2 will influence the longevity of water table development. Notwithstanding, the main science question is to examine the co-evolution of a vegetation-hillslope system. As such, knowledge of the lower boundary in this sense trumps bedrock permeability "realness" as an impermeable lower boundary shifts our focus exclusively to the soil mantle and ecohydrological processes within it. Thereby, the degrees of freedom about these biological-hydrological interactions are reduced and our system is greatly simplified in terms of its response.
We chose a convergent hollow as our topographic blueprint mainly to increase options for hydrological and ecological heterogeneity at the scale of our experiment. The slope angle range that we could reproduce at Biosphere 2 would rarely if ever form such a distinct convergent hollow (Carson and Kirkby, 1972). Nevertheless, we chose a convergent hollow as hillslope shape (as opposed to a planar slope) to provide some heterogeneity in radiative input and soil moisture conditions. These subtle differences in incident radiation and upslope contributing area for water flux will exert qualitative changes on slope processes. With the other factors held constant (soil type, soil depth, bedrock permeability, etc.), the spatial patterns stemming from the convergent topography will allow comparison of responses within treatments. Spatial patterns of soil moisture at the hillslope scale (Tromp-van Meerveld and McDonnell, 2006) and catchment scale (e.g. Wilson et al., 2004) have shown qualitatively how vegetation begins to obscure topographic controls on moisture distribution after leaf-out. Within the Biosphere 2 experimental design, we will be able to quantify such influences and strike at the mechanistic controls of vegetation on soil water dynamics, and vice versa. Consequently, a planar slope would greatly restrict our ability to examine coupled processes and reactions, given that we would be restricted to only one solar aspect realization.

\subsection{How modeling has informed design}

Modeling was a critical part of the design process. The modeling work so far has suggested that the proposed hillslope design is likely to meet the principal design considerations. It is capable of supporting vegetation under the semi-arid climates of the South-West (B1, B4). It will permit the development of transient lateral connectivity across the hillslopes (B3) and it will facilitate spatial and temporal variability in soil moisture (B2, B5). Together with the vegetation, the evolution of the soil profile is likely to produce spatial heterogeneity in hydrologic properties and behavior (A1). The simulations suggest that the current design is also likely to be stable geomorphically $(\mathrm{C} 1)$ while remaining technically feasible (C2). Finally it embodies the principles of simplicity and elegance (A2), and will allow further refinements to be made to the experimental design in the selection of the climate and vegetation treatments across the three hillslopes and through time.

It is notable that the behavior of the hillslope, as predicted by the modeling, is strongly seasonal, and does not show a significant response to individual events. Given that the characteristic subsurface flow timescale - given by the time for a kinematic wave to travel through the hillslope (Harman and Sivapalan, 2009) - is on the order of 50 days, this is unsurprising. The smoothly-varying pressure heads deeper in the soil profile (Fig. 4) suggest that the unsaturated zone is also playing a role in filtering the high-frequency variability. In essence, though, the lack of an event-scale response can be 
attributed to the lack of any threshold-like runoff mechanism, like overland flow, bedrock storage or preferential flow, to turn on in sufficiently large or intense storms. Such mechanisms, particularly preferential flow, may develop in the hillslope over time once vegetation and geochemical changes begin to alter the properties of the hillslope, leading to the formation of an event-scale response.

\subsection{Projecting future behavior of the Biosphere 2 hillslopes}

Due to the large uncertainties about the feedback between hydrology and geochemistry, biology and geomorphology, however, the design modeling could not be used to project the hydrologic behavior of the hillslope into the future with any degree of confidence. These uncertainties are the raison d'être of the Biosphere 2 Hillslope Experiment, and it is the complex behavior not fully anticipated in advance that will likely produce the greatest advances in our knowledge. From a hydrologic perspective, some of the outstanding questions about the evolution of the Biosphere 2 hillslopes are:

- How will the vegetation dynamics adapt to the hydrologic conditions and in turn alter the water balance through transpiration?

- How will the structure of the soil change over time due to geochemical and biological factors? How will these changes in turn alter the hydraulic properties and flow pathways through the subsurface (including the formation of preferential flow networks)?

- How will spatial patterns of occasional overland flow and infiltration drive changes in surface morphology and soil properties, and how will these changes alter the surface water and energy balance?

- How will these effects combine to create evolving patterns of variability and connectivity in the unsaturated and saturated zones of the subsurface?

- What will be the integrated effect of these factors on the signatures of discharge variability and water chemistry at the whole-hillslope scale?

Work is already underway to address some of these uncertainties using available models, and their results will generate more confidence in the design, and more refinements to the final experimental set-up. The geochemical model CrunchFlow07 (Steefel and Lasaga, 1994) has been used to examine how the soil oxygen levels, $\mathrm{pH}$, and mineralogy will change over time, including the production of secondary clay minerals (Dontsova et al., 2009). The distributed hydrology dynamic vegetation model tRIBS-VEGGIE (Ivanov et al., 2008 ) is being used to investigate how vegetation-hydrology feedbacks over time affect water-use and primary productivity (Ivanov et al., 2009).
The Biosphere 2 experiment itself aims to overcome these uncertainties in two ways. One way is bottom-up, through the development and testing of an integrated process model that can reproduce and predict the evolution of the hillslope hydrologic behavior through time, along with the evolution of the geochemical, biological, pedological and geomorphic systems. The other is through observing and interrogating patterns that emerge in the data (top down), and using these for the formulation of new theory, hypotheses and models.

\section{Conclusions}

The Biosphere 2 Hillslope Experiment is being designed to address fundamental questions about how natural landscape processes interact and co-evolve through time. The Biosphere 2 facility's unique spatial scale provides the opportunity for controlled experiments at a large scale, bridging the gap between controlled, laboratory-scale experiments and field experiments under natural conditions. The first phase of the experiment has included pre-construction modeling efforts in hydrology, ecology and geochemistry that aim at supporting the design and construction process of the hillslopes as well as providing initial model predictions of the anticipated evolution of the vegetation-hillslope systems.

The Biosphere 2 Hillslope Experiment will serve as an excellent basis to test hypotheses, validate existing models and develop coupled process models. Furthermore, the aim of this extraordinary community effort is to not only observe and qualitatively describe interactions and feedbacks between hydrology, soil evolution, biota and geomorphology but also to quantify the relationships and mechanisms, thereby advancing our ability to predict the evolution of hydrologic systems in general (Troch et al., 2009).

Acknowledgements. We would like to thank the participants of the Biosphere 2 Hillslope Experiment planning workshops in 2007 and 2008 for fruitful discussions and comments on this manuscript (complete list of participants at http://www.b2science.org/earth/research-hillslope.html). We are grateful to Travis Huxman, Director of B2 Earthscience, and the B2 Earthscience Science Steering Committee for their support of this work. This work was also supported by the NSF-funded Hydrologic Synthesis Project at the University of Illinois at Urbana-Champaign.

Edited by: F. Laio 


\section{References}

Anderson, M. G. and Burt, T. P.: A laboratory model to investigate the soil moisture conditions on a draining slope, J. Hydrol., 33, 383-390, 1977.

Bishop, K. H. and Hultberg, H.: Reversing Acidification in a Forest Ecosystem - the Gardsjon Covered Catchment, Ambio, 24, 8591, 1995.

Brantley, S. L., Goldhaber, M. B., and Ragnarsdottir, K. V.: Crossing disciplines and scales to understand the Critical Zone, Elements, 3, 307-314, 2007.

Brown-Mitic, C., Shuttleworth, W. J., Harlow, R. C., Petti, J., Burke, E., and Bales, R.: Seasonal water dynamics of a sky island subalpine forest in semi-arid southwestern United States, J. Arid Environ., 69, 237-258, 2007.

Buttle, J. M. and Turcotte, D. S.: Runoff processes on a forested slope on the Canadian shield, Nord. Hydrol., 30, 1-20, 1999.

Buttle, J. M. and McDonald, D. J.: Coupled vertical and lateral preferential flow on a forested slope, Water Resour. Res., 38, 1060, doi:10.1029/2001WR000773, 2002.

Carsel, R. F. and Parrish, R. S.: Developing Joint ProbabilityDistributions of Soil-Water Retention Characteristics, Water Resour. Res., 24, 755-769, 1988.

Carson, M. A. and Kirkby, M. J.: Hillslope form and process, Cambridge University Press, Cambridge, 475 pp., 1972.

Dontsova, K., Steefel, C. I., Desilets, S., Thompson, A., and Chorover, J.: Coupled modeling of hydrologic and geochemical fluxes for prediction of solid phase evolution in the Biosphere 2 hillslope experiment, Hydrol. Earth Syst. Sci. Discuss., 6, 44494483, 2009, http://www.hydrol-earth-syst-sci-discuss.net/6/4449/2009/.

Dunn, S. M., Freer, J., Weiler, M., Kirkby, M. J., Seibert, J., Quinn, P. F., Lischeid, G., Tetzlaff, D., and Soulsby, C.: Conceptualization in catchment modelling: simply learning?, Hydrol. Process., 22, 2389-2393, 2008.

Ebel, B. A., Loague, K., Montgomery, D. R., and Dietrich, W. E.: Physics-based continuous simulation of long-term near-surface hydrologic response for the Coos Bay experimental catchment, Water Resour. Res., 44, W07417, doi:10.1029/2007WR006442, 2008.

Eberhardt, L. L. and Thomas, J. M.: Designing Environmental Field Studies, Ecol. Monogr., 61, 53-73, 1991.

Fiori, A. and Russo, D.: Numerical analyses of subsurface flow in a steep hillslope under rainfall: The role of the spatial heterogeneity of the formation hydraulic properties, Water Resour. Res., 43, W07445, doi:10.1029/2006WR005365, 2007.

Freer, J., McDonnell, J. J., Beven, K. J., Peters, N. E., Burns, D. A., Hooper, R. P., Aulenbach, B., and Kendall, C.: The role of bedrock topography on subsurface storm flow, Water Resour. Res., 38, 1269, doi:10.1029/2001WR000872, 2002.

Gerwin, W., Raab, T., Biemelt, D., Bens, O., and Httl, R. F.: The artificial water catchment "Chicken Creek" as an observatory for critical zone processes and structures, Hydrol. Earth Syst. Sci. Discuss., 6, 1769-1795, 2009,

http://www.hydrol-earth-syst-sci-discuss.net/6/1769/2009/.

Harman, C. and Sivapalan, M.: A similarity framework to assess controls on shallow subsurface flow dynamics in hillslopes, Water Resour. Res., 45, W01417, doi:10.1029/2008WR007067, 2009.

Hewlett, J. D. and Hibbert, A. R.: Moisture and energy conditions within a sloping soil mass during drainage, J. Geophys. Res., 68, 1081-1087, 1963.

Hopp, L. and McDonnell, J. J.: Connectivity at the hillslope scale: Identifying interactions between storm size, bedrock permeability, slope angle and soil depth, J. Hydrol., 376, 378-391, doi:10.1016/j.jhydrol.2009.07.047, 2009.

Huxman, T., Troch, P., Chorover, J., Breshears, D. D., Saleska, S., Pelletier, J., Zeng, X., and Espeleta, J.: The Hills are Alive: Earth Science in a Controlled Environment, EOS, Transactions, American Geophysical Union, 90, p. 120, 2009.

Ivanov, V. Y., Bras, R. L., and Vivoni, E. R.: Vegetation-hydrology dynamics in complex terrain of semiarid areas: 1. A mechanistic approach to modeling dynamic feedbacks, Water Resour. Res., 44, W03429, doi:10.1029/2006WR005588, 2008.

Ivanov, V. Y., Fatichi, S., Jenerette, G. D., Espeleta, J. F., Troch, P. A., and Huxman, T. E.: Hysteresis of soil moisture spatial heterogeneity and the "homogenizing" effect of vegetation, Water Resour. Res., in review, 2009.

Kampf, S. K. and Burges, S. J.: Parameter estimation for a physics-based distributed hydrologic model using measured outflow fluxes and internal moisture states, Water Resour. Res., 43, W12414, doi:10.1029/2006WR005605, 2007.

Kendall, C., McDonnell, J. J., and Gu, W. Z.: A look inside 'black box' hydrograph separation models: a study at the Hydrohill catchment, Hydrol. Process., 15, 1877-1902, 2001.

Kosugi, K., Uchida, T., and Mizuyama, T.: Numerical calculation of soil pipe flow and its effect on water dynamics in a slope, Hydrol. Process., 18, 777-789, 2004.

Kumar, P.: Variability, Feedback, and Cooperative Process Dynamics: Elements of a Unifying Hydrologic Theory, Geography Compass, 1, 1338-1360, 2007.

Lin, H., Bouma, J., Pachepsky, Y., Western, A., Thompson, J., van Genuchten, R., Vogel, H. J., and Lilly, A.: Hydropedology: Synergistic integration of pedology and hydrology, Water Resour. Res., 42, W05301, doi:10.1029/2005WR004085, 2006.

Lyon, S. W., Desilets, S. L. E., and Troch, P. A.: Characterizing the response of a catchment to an extreme rainfall event using hydrometric and isotopic data, Water Resour. Res., 44, W06413, doi:10.1029/2007WR006259, 2008.

McClain, M. E., Boyer, E. W., Dent, C. L., Gergel, S. E., Grimm, N. B., Groffman, P. M., Hart, S. C., Harvey, J. W., Johnston, C. A., Mayorga, E., McDowell, W. H., and Pinay, G.: Biogeochemical hot spots and hot moments at the interface of terrestrial and aquatic ecosystems, Ecosystems, 6, 301-312, 2003.

McDonnell, J. J., Sivapalan, M., Vache, K., Dunn, S., Grant, G., Haggerty, R., Hinz, C., Hooper, R., Kirchner, J., Roderick, M. L., Selker, J., and Weiler, M.: Moving beyond heterogeneity and process complexity: A new vision for watershed hydrology, Water Resour. Res., 43, W07301, doi:10.1029/2006WR005467, 2007.

McGuire, K. J., Weiler, M., and McDonnell, J. J.: Integrating tracer experiments with modeling to assess runoff processes and water transit times, Adv. Water Resour., 30, 824-837, 2007.

McHale, M. R., McDonnell, J. J., Mitchell, M. J., and Cirmo, C. P.: A field-based study of soil water and groundwater nitrate release in an Adirondack forested watershed, Water Resour. Res., 38, 1031, doi:10.1029/2000WR000102, 2002.

McNamara, J. P., Chandler, D., Seyfried, M., and Achet, S.: Soil moisture states, lateral flow, and streamflow generation in a semi- 
arid, snowmelt-driven catchment, Hydrol. Process., 19, 40234038, 2005.

MEA: Millennium Ecosystem Assessment. Ecosystems and Human Well-being: Desertification Synthesis, World Resources Institute, Washington, DC, 2005.

Monteith, J. L.: Evaporation and Surface-Temperature, Q. J. Roy. Meteor. Soc., 107, 1-27, 1981.

Monteith, J. L. and Unsworth, M. H.: Principles of Environmental Physics, Edward Arnold, London, 1990.

Newman, B. D., Campbell, A. R., and Wilcox, B. P.: Lateral subsurface flow pathways in a semiarid ponderosa pine hillslope, Water Resour. Res., 34, 3485-3496, 1998.

Platt, J. R.: Strong inference, Science, 146, 347-353, 1964.

Reynolds, J. F., Smith, D. M. S., Lambin, E. F., Turner, B. L., II, Mortimore, M., Batterbury, S. P. J., Downing, T. E., Dowlatabadi, H., Fernandez, R. J., Herrick, J. E., HuberSannwald, E., Jiang, H., Leemans, R., Lynam, T., Maestre, F. T., Ayarza, M., and Walker, B.: Global Desertification: Building a Science for Dryland Development, Science, 316, 847-851, doi:10.1126/science.1131634, 2007.

Schaap, M. G., Leij, F. J., and van Genuchten, M. T.: ROSETTA: a computer program for estimating soil hydraulic parameters with hierarchical pedotransfer functions, J. Hydrol., 251, 163-176, 2001.

Scott, R. L., Shuttleworth, W. J., Keefer, T. O., and Warrick, A. W.: Modeling multiyear observations of soil moisture recharge in the semiarid American Southwest, Water Resour. Res., 36, 2233$2247,2000$.

Simunek, J., van Genuchten, M. T., and Sejna, M.: The HYDRUS software package for simulating two- and three-dimensional movement of water, heat, and multiple solutes in variablysaturated media: Technical manual, Version 1.0., PC-Progress, Prague, Czech Republic, 213 pp., 2006.

Simunek, J., van Genuchten, M. T., and Sejna, M.: Development and applications of the HYDRUS and STANMOD software packages and related codes, Vadose Zone J., 7, 587-600, 2008.

Sivapalan, M.: Pattern, Process and Function: Elements of a Unified Theory of Hydrology at the Catchment Scale, in: Encyclopedia of Hydrological Sciences, edited by: Anderson, M. G., John Wiley \& Sons Ltd., 193-219, 2005.

Soulsby, C., Neal, C., Laudon, H., Burns, D. A., Merot, P., Bonell, M., Dunn, S. M., and Tetzlaff, D.: Catchment data for process conceptualization: simply not enough?, Hydrol. Process., 22, 2057-2061, 2008.

Steefel, C. I. and Lasaga, A. C.: A Coupled Model for Transport of Multiple Chemical-Species and Kinetic Precipitation Dissolution Reactions with Application to Reactive Flow in SinglePhase Hydrothermal Systems, Am. J. Sci., 294, 529-592, 1994.

Struthers, I., Hinz, C., and Sivapalan, M.: A multiple wetting front gravitational infiltration and redistribution model for water balance applications, Water Resour. Res., 42, W06406, doi:10.1029/2005WR004645, 2006.

Tani, M.: Runoff generation processes estimated from hydrological observations on a steep forested hillslope with a thin soil layer, J. Hydrol., 200, 84-109, 1997.
Tetzlaff, D., McDonnell, J. J., Uhlenbrook, S., McGuire, K. J., Bogaart, P. W., Naef, F., Baird, A. J., Dunn, S. M., and Soulsby, C.: Conceptualizing catchment processes: simply too complex?, Hydrol. Process., 22, 1727-1730, 2008.

Troch, P., Carrillo, G. A., Heidbüchel, I., Rajagopal, S., Switanek, M., Volkmann, T. H. M., and Yaeger, M.: Dealing with Landscape Heterogeneity in Watershed Hydrology: A Review of Recent Progress toward New Hydrological Theory, Geography Compass, 3, 375-392, 2009.

Troch, P. A., Paniconi, C., and van Loon, E. E.: Hillslopestorage Boussinesq model for subsurface flow and variable source areas along complex hillslopes: 1. Formulation and characteristic response, Water Resour. Res., 39, 1316, doi:10.1029/2002WR001728, 2003.

Tromp-van Meerveld, H. J. and McDonnell, J. J.: On the interrelations between topography, soil depth, soil moisture, transpiration rates and species distribution at the hillslope scale, Adv. Water Resour., 29, 293-310, 2006.

Tromp-van Meerveld, H. J. and McDonnell, J. J.: Threshold relations in subsurface stormflow: 1. A 147-storm analysis of the Panola hillslope, Water Resour. Res., 42, W02410, doi:10.1029/02004WR003778, 2006a.

Tromp-van Meerveld, H. J. and McDonnell, J. J.: Threshold relations in subsurface stormflow: 2. The fill and spill hypothesis, Water Resour. Res., 42, W02411, doi:10.1029/02004WR003800, 2006b.

Tromp-van Meerveld, H. J., Peters, N. E., and McDonnell, J. J.: Effect of bedrock permeability on subsurface stormflow and the water balance of a trenched hillslope at the Panola Mountain Research Watershed, Georgia, USA, Hydrol. Process., 21, 750-769, 2007.

Uchida, T., Meerveld, I. T., and McDonnell, J. J.: The role of lateral pipe flow in hillslope runoff response: an intercomparison of non-linear hillslope response, J. Hydrol., 311, 117-133, 2005.

van Genuchten, M. T.: A closed-form equation for predicting the hydraulic conductivity of unsaturated soils, Soil Sci. Soc. Am. J., 44, 892-898, 1980.

van Verseveld, W. J., McDonnell, J. J., and Lajtha, K.: A mechanistic assessment of nutrient flushing at the catchment scale, J. Hydrol., 358, 268-287, 2008.

Wagener, T., Sivapalan, M., Troch, P., and Woods, R.: Catchment Classification and Hydrologic Similarity, Geography Compass, 1, 901-931, 2007.

Wilson, D. J., Western, A. W., and Grayson, R. B.: Identifying and quantifying sources of variability in temporal and spatial soil moisture observations, Water Resour. Res., 40, W02507, doi:10.1029/2003WR002306, 2004.

Woods, R. and Rowe, L.: The changing spatial variability of subsurface flow across a hillside, J. Hydrol. (NZ), 35, 49-84, 1996. 